\title{
PERCEPÇÃO DA POPULAÇÃO QUANTO À ARBORIZAÇÃO NA ZONA CENTRAL HISTÓRICA DE ALTAMIRA-PA
}

\section{POPULATION'S PERCEPTION IN RELATION TO AFFORESTATION IN CENTRAL HISTORIC AREA OF ALTAMIRA-PA}

\author{
Eliézer Cláudio Ribeiro Silva ${ }^{1}$; Fiamma Buchinger Alves²; Igor Itaci Stelmastchuk da Silva³; \\ Bruno Chaves Carvalho ${ }^{4}$; Juliano Matheus Almeida ${ }^{5}$; Rafael Caldeira Magalhães ${ }^{6}$
}

\begin{abstract}
RESUMO
O aumento populacional que está ocorrendo nos últimos cinco anos na cidade Altamira-PA, provocou a expansão das fronteiras urbanas sem o devido planejamento, sendo a arborização um fator importante para a contribuição na melhoria desses ambientes. O objetivo do trabalho é elaborar um diagnóstico da percepção das pessoas em relação à arborização na Zona Central Histórica de Altamira-PA. Esse diagnóstico foi feito através de entrevistas em campo com perguntas quali-quantitativas e mapeamento das árvores adultas. Foram registradas 272 árvores e mapeadas com o auxílio do software QGIS 2.2. A ZCH apresentou um Índice de Arborização por Quilômetro de Calçada Arborizada de 13,23 ou seja, a quantidade de árvores nessa zona é insuficiente, quando o ideal seria de 100 árvores por quilômetro. Os entrevistados relataram que há dez anos a quantidade de árvores no bairro era maior, principalmente com mangueiras (Mangifera indica), $67 \%$ deles se demonstraram insatisfeitos com a arborização, atualmente, e apenas $12 \%$ consideraram a quantidade de árvores ótima. O planejamento da arborização pode não estar sendo tão atentado nos projetos de compensação ambiental da UHE Belo Monte, sendo que o mesmo é fundamental para qualquer sistema urbano, devido aos seus benefícios para a população.
\end{abstract}

Palavras-chave: Diagnóstico; Expansão urbana; Árvores; UHE Belo Monte.

\section{ABSTRACT}

The population growth that is occurring in the last five years in Altamira-PA city, led to the expansion of urban boundaries without proper planning, thus afforestation is an important factor for the contribution to the improvement of these environments. The objective is to elaborate a diagnosis of the perception of people in relation to afforestation in the Historic Central Zone Altamira-PA. This diagnosis was made through interviews in the field with qualitative and quantitative questions and mapping of mature trees. There were logged 272 trees and mapped using the QGIS 2.2 software. The ZCH presented a Afforestation Index by Kilometer of Street Trees of 13.23, ie the amount of trees in the area is insufficient, while the ideal would be 100 trees per kilometer. Respondents reported that ten years ago, the amount of trees in the neighborhood was bigger, especially with mango trees (Mangifera indica), $67 \%$ of them showed dissatisfied with trees, today, and only $12 \%$ thought that the amount of trees was great. Planning for afforestation cannot being well attempt in environmental offset projects of UHE Belo Monte, being that it is essential for any urban system, because of its benefits to the population.

Keywords: Diagnosis; Urban sprawl; Trees; UHE Belo Monte.

Recebido em 29.11.2015 e aceito em 06.01.2016

1 Graduando em Engenharia Ambiental na Universidade do Estado do Pará - UEPA, Altamira/PA, eliezer_claudio@hotmail.com 2 Graduanda em Engenharia Ambiental Universidade do Estado do Pará - UEPA, Altamira/PA fbuchinger@hotmail.com 3 Graduando em Engenharia Ambiental na Universidade do Estado do Pará - UEPA, Altamira/PA, igor.itaci@gmail.com 4 Graduando em Engenharia Ambiental na Universidade do Estado do Pará - UEPA, Altamira/PA, brun0_carvalho@hotmail.com 5 Graduando em Engenharia Ambiental na Universidade do Estado do Pará- UEPA, Altamira/PA, podiaestadurmindo@gmail.com 6 Doutorando em Saneamento, Meio Ambiente e Recursos Hídricos da Universidade Federal de Minas Gerais - UFMG, Belo Horizonte/MG, ambienterfl@gmail.com 


\section{INTRODUÇÃO}

O aumento da população nas cidades requer uma demanda maior por área para a urbanização, assim as pessoas ficam cada vez mais afastadas das áreas verdes. O meio ambiente mais urbanizado das cidades fica cada dia mais hostil, o que acaba por trazer prejuízos à saúde humana, com isso a população percebe a importância das áreas verdes para uma maior qualidade de vida (VALENTIN, 2010).

Segundo o IBGE (2010), o Brasil apresenta $84,86 \%$ de sua população vivendo na zona urbana e, para Altamira-PA, esse valor corresponde a $84,88 \%$. As estimativas do IBGE para a população do município para o ano de 2015 é de 108 mil e da Prefeitura Municipal de Altamira-PA é de 150 mil, devido a instalação da UHE Belo monte (Usina Hidroelétrica de Belo Monte). Por esses motivos, a porcentagem de população urbana pode ser bem maior do que a indicada em 2010 pelo IBGE. Logo, a razão dos esforços para a arborização é aprimorar o ambiente de uma população cada vez mais urbana (OLDFIELD et al., 2013).

Segundo Souza, Cardoso e Silva (2013), a arborização de cidades surgiu com o intuito de proporcionar ao homem os seguintes benefícios: o sombreamento, a melhoria no microclima, proporcionar a recreação e o lazer, ou seja, proporcionar bem estar das sociedades que vivem nas cidades. Árvores que acompanham o sistema viário ou são encontradas em áreas livres públicas exercem a função de corredor ecológico, trazendo benefícios ao microclima da cidade, qualidade do ar, retenção do fluxo de ar e redução de ruído.

O ser humano tende a revelar suas expectativas, anseios, julgamentos e condutas com relação às árvores no meio urbano, por isso o estudo da percepção ambiental é de fundamental importância à gestão da arborização urbana (SILVA; BATISTA; BATISTA, 2013).

Costa e Colesanti (2011) propõem que os estudos de percepção ambiental e a busca por compreender como a população enxerga estes espaços, o que ela anseia, e, que relação estabelece com estes espaços são alternativas para que as áreas verdes públicas como praças, parques urbanos e jardins atendam às necessidades e anseios da população, para serem desejados e mantidos pela população.

A arborização viária ou de rua, embora desempenhe uma função essencial e insubstituível para o bem estar urbano, quando mal planejada pode causar vários prejuízos aos atores que estão inseridos no meio urbano, como por exemplo a dificuldade de circulação de pessoas nas calçadas, dificuldade na visualização de placas de sinalização de trânsito e o contato das copas das árvores na fiação elétrica (MAYER; FILHO; BOBROWSKI, 2015). 
Os trabalhos realizados por Parry et al. (2012), Pizziolo et al. (2014), Gerstenberg e Hofmann (2015), Silva, Batista e Batista (2013) e Conway e Bang (2014) são alguns exemplos de trabalhos que abordam e contribuem para o tema arborização urbana.

A realização do presente trabalho no centro histórico da cidade de Altamira-PA é justificada principalmente por que nos tempos atuais a arborização se tornou um elemento indispensável, no contexto do planejamento urbano e da melhoria da qualidade de vida nos grandes centros urbanos. O objetivo é elaborar um diagnóstico da percepção das pessoas em relação à arborização na Zona Central Histórica de Altamira-PA.

\section{MATERIAL E MÉTODOS}

O trabalho foi realizado no município de Altamira (Figura 1), que está localizado ao oeste do Estado do Pará, com a coordenadas geográficas da sede municipal $03^{\circ} 12^{\prime} 00^{\prime \prime} \mathrm{S}$ e 52¹3'45" O, à margem esquerda do Rio Xingu, a uma altitude de 74 m (MOURA; RIBEIRO, 2009).

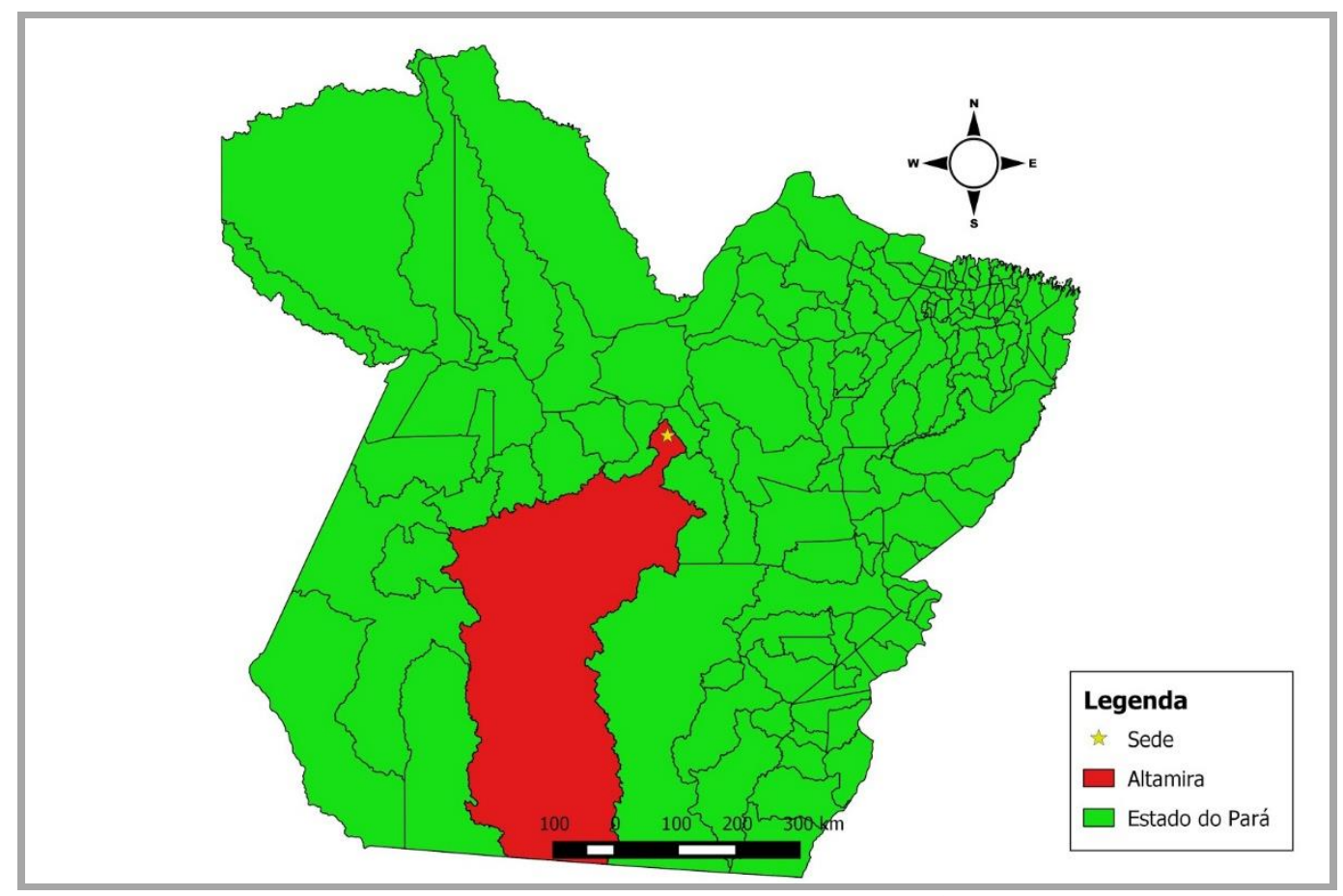

Fonte: IBGE, 2013. Elaboração própria.

Figura 1. Localização do Município de Altamira-PA

Figure 1. Location of the municipality of Altamira, PA

Os solos predominantes nesse local são os Neossolos flúvicos, uma associação dos solos Latossolo Amarelo/Argissolo Vermelho amarelo e o Nitossolo Vermelho. O clima é do 
tipo equatorial Am com temperaturas médias de $27,3^{\circ} \mathrm{C}$ e a precipitação pluviométrica anual gira em torno de $2.123 \mathrm{~mm}$ (PARRY et al., 2012).

A área estudada é a Zona Central Histórica $(\mathrm{ZCH})$ de Altamira-PA (Figura 2), que faz parte do Centro do município e foi definida pelo Plano Diretor de Altamira de 2003. Essa Zona, segundo o Plano, é constituída por quatro ruas: Sete de setembro, Magalhães Barata, Primeiro de Janeiro e Coronel José Porfírio; uma avenida: Djalma Dutra; oito travessas: Pedro Gomes, Agrário Cavalcante, Dez de Novembro, Coronel Tancredo, Lindolfo Aranha, Comandante Castilho, Paula Marquês e Coronel Gaioso; e uma Alameda: Heroito de Medeiros.

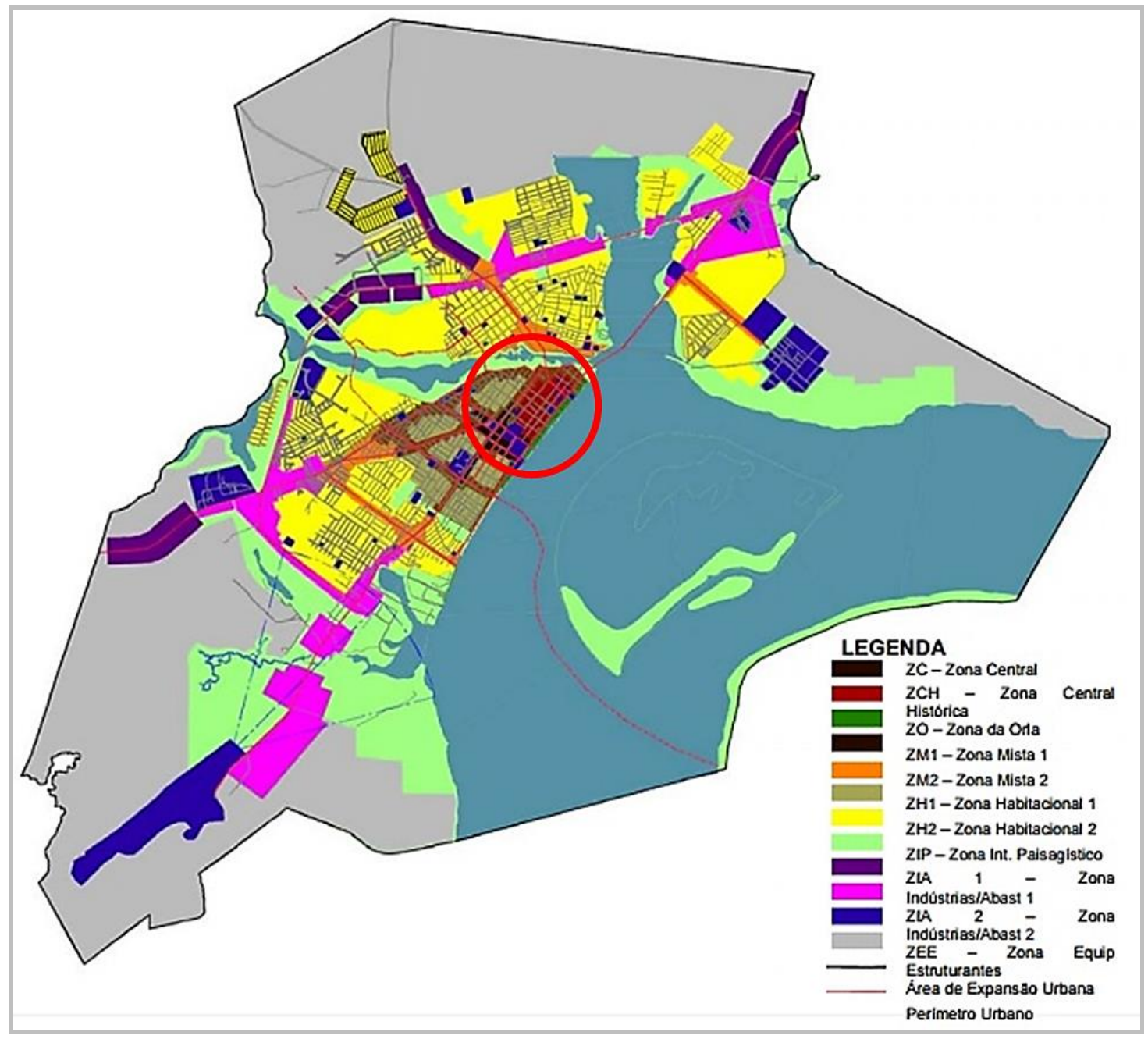

Fonte: Prefeitura Municipal de Altamira, 2010.

Figura 2. Zona Histórica Central de Altamira-PA

Figure 2. Historic City Center of Altamira-PA

A ZCH, segundo o Plano Diretor de Altamira de 2003, é "área onde se pretende incentivar a proteção do patrimônio cultural, mantendo a ocupação habitacional das categorias de uso do solo residencial da subcategoria UH - Habitações Unifamiliares - e 
comércio e prestação de serviços da subcategoria CS 1 - Escritórios e consultórios de profissionais liberais, serviços pessoais e domiciliares, comércio de consumo local, serviços socioculturais, comércio varejista diversificado, serviços pessoais, de saúde e educação, serviços de hospedagem e atividades associadas à recreação. Deverá ser permitida a transferência do potencial construtivo para as edificações da Zona Central Histórica que forem objetos de obras de restauro, e que tenham recuperado e conservado as características originais das fachadas e telhados, ficando a cargo do Executivo Municipal a regulamentação desse benefício".

A pesquisa realizada é de caráter exploratório e de perspectiva quali-quantitativa. Foram realizadas visitas a campo, na $\mathrm{ZCH}$. Houve aplicação de questionários que continham perguntas abertas e fechadas, e os mesmos foram aplicados durante um dia com os moradores, comerciantes e transeuntes (amostra intencional) que transitam na Zona Central Histórica de Altamira.

As entrevistas foram realizadas em locais distribuídos espacialmente, conforme mostra a Figura 3. O questionário possuía os seguintes itens: 1 - Idade do entrevistado; 2 Característica de entrevistado (morador, comerciante ou pedestre); 3 - Classificação da quantidade de árvores a um diâmetro circundante de $1 \mathrm{~m}$ a sua volta (ruim $\leq 5$, razoável $>5 \mathrm{e}$ $\leq 10$ ou ótimo > 10); 4 - Vantagens e desvantagens da arborização (sombra, redução de calor, redução da poluição do ar, melhoria visual, valorização imobiliária, e alimentação); 5 Espécie de árvore que desejaria na área; 6 - Situação da arborização há dez anos atrás e a expectativa para os próximos dez anos. Depois de realizadas as entrevistas prosseguiram-se a tabulação dos dados obtidos e análise a partir de planilhas informatizadas

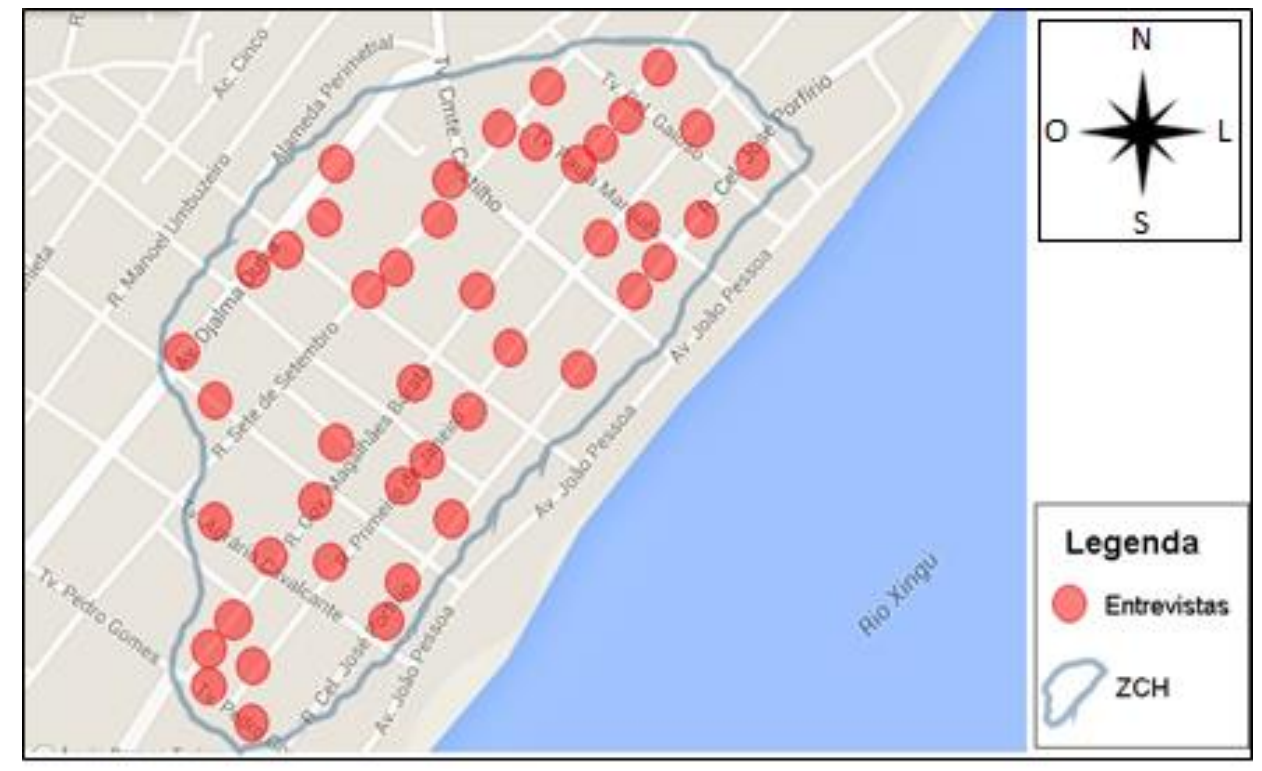

Figura 3. Distribuição dos locais que foram aplicados os questionários Figure 3. Distribution of locals where questionnaires were applied 
Ainda nesse trabalho, realizou-se o georreferenciamento dos indivíduos árbóreos com o uso de GPS Garmin GPSmap 62s (sistema de projeção UTM datum WGS84), para a geração de um mapa temático da distribuição dos indivíduos, através do software QGIS 2.2 Valmiera. Os tipos dos indivíduos arbóreos escolhidos foram as árvores na fase adulta, desconsiderando-se as herbáceas e arbustos, por causa da sua predominância.

Com os dados da distribuição dos indivíduos nas ruas da $\mathrm{ZCH}$, pode-se analisar como referência ideal de árvores por quilômetro de calçada, a quantidade de 100 árvores, correspondendo a 1 árvore na frente de cada casa, estimando a média de terrenos urbanos no Brasil como sendo 10 metros. Esse é o Índice de Árvores por Quilômetro de Calçada Arborizada (IAQC) utilizado por Lima Neto (2011), no qual divide-se o número de árvores pela extensão das calçadas (em km).

\section{RESULTADOS E DISCUSSÃO}

Foram catalogadas 272 árvores com o uso do GPS e, em seguida, as mesmas foram mapeadas através de geoprocessamento como uso do software QGIS 2.2, conforme a Figura 4. Dessa forma, pôde-se ter uma visão abrangente da distribuição das árvores na Zona pesquisada, observando-se uma ausência de árvores na direção norte da ZCH. A representação espacial das árvores na área de estudo favorece o direcionamento do planejamento da arborização urbana.

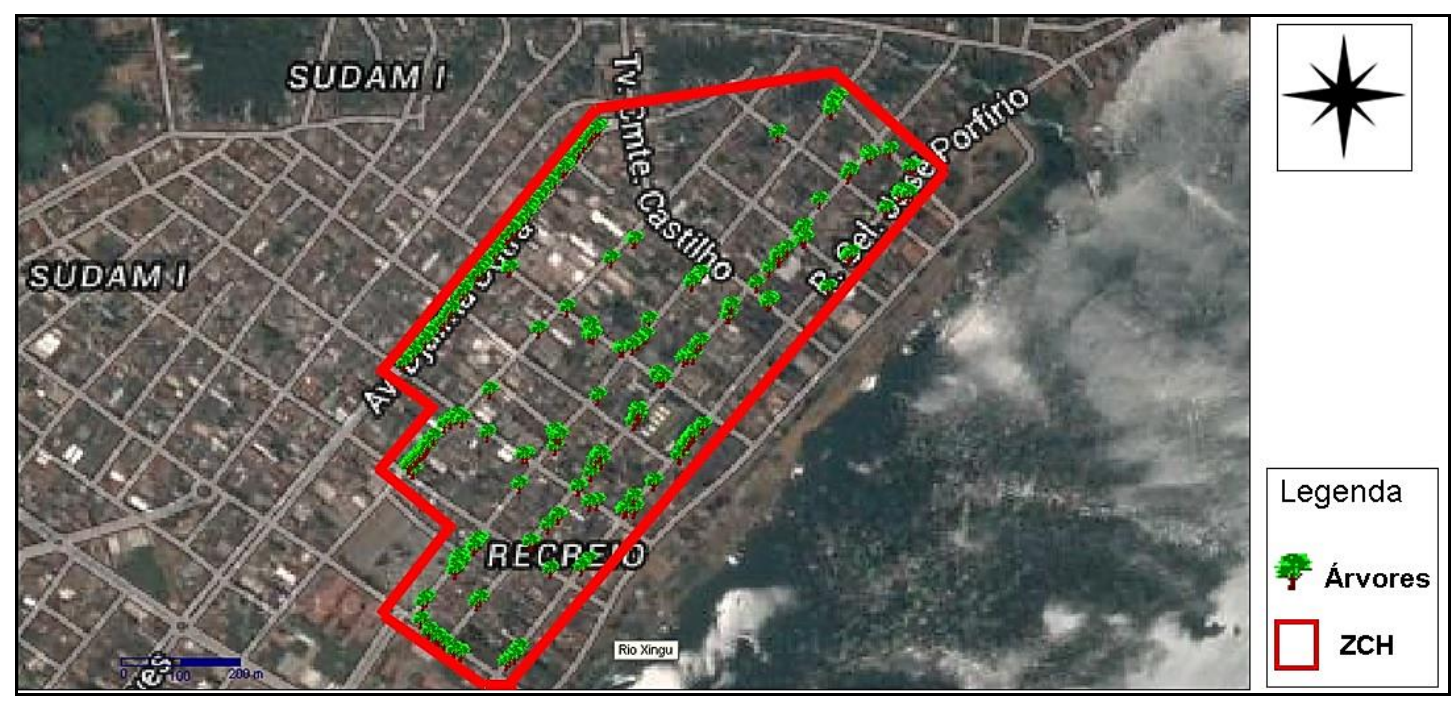

Figura 4. Distribuição das árvores dentro da Zona Central Histórica

Figure 4. Distribution of trees in the Historic Central Zone 
O perímetro da ZCH está destacado na Figura 4 e corresponde a $434.837 \mathrm{~m}^{2}(43,48$ ha) e a extensão total dos trechos das ruas que estão dentro do perímetro estudado é de aproximadamente $8 \mathrm{~km}$ (Tabela 1). A extensão das ruas foi também calculada no QGIS, sendo que os dados da extensão das calçadas foram obtidos mutiplicando-se por 2 a extensão das ruas, com exceção da Avenida Djalma Dutra que teve o valor da extensão calçada obtido pela multiplicação por 3 , devido a mesma apresentar duas ruas, de sentidos opostos, dividas por uma calçada.

Tabela 1. Índice de árvores por quilômetro de calçada

Table 1. Index of trees per kilometer of pavement

\begin{tabular}{lcccc}
\hline Trecho & $\begin{array}{c}\text { Extensão } \\
(\mathbf{k m})\end{array}$ & $\begin{array}{c}\text { Calçadas } \\
(\mathbf{k m})\end{array}$ & $\begin{array}{c}\text { Quantidade } \\
\text { de árvores }\end{array}$ & IAQC \\
\hline Trav. Coronel Gaioso & 0,28 & 0,56 & 1 & 1,79 \\
Trav. Comandante Castilho & 0,44 & 0,88 & 3 & 3,41 \\
Alameda Heroito de Medeiros & 0,13 & 0,26 & 1 & 3,85 \\
Trav. Agrário Cavalcante & 0,33 & 0,66 & 3 & 4,55 \\
Trav. 10 de Novembro & 0,44 & 0,88 & 6 & 6,82 \\
Trav. Paula Marques & 0,28 & 0,56 & 4 & 7,14 \\
Trav. Pedro Lemos & 0,28 & 0,56 & 6 & 10,71 \\
Trav. Lindolfo Aranha & 0,45 & 0,9 & 16 & 17,78 \\
Rua Magalhães Barata & 0,97 & 1,94 & 37 & 19,07 \\
Rua Sete de Setembro & 0,87 & 1,74 & 34 & 19,54 \\
Rua Coronel José Porfírio & 1,13 & 2,26 & 47 & 20,80 \\
Rua Primeiro de Janeiro & 1,14 & 2,28 & 50 & 21,93 \\
Trav. Pedro Gomes & 0,18 & 0,36 & 10 & 27,78 \\
Av. Djalma Dutra & 0,54 & 1,62 & 54 & 33,33 \\
\hline TOTAL & $\mathbf{7 , 9 0}$ & $\mathbf{1 6 , 3 4}$ & $\mathbf{2 7 2}$ & $\mathbf{1 3 , 2 3}$ (média) \\
\hline
\end{tabular}

A Tabela 1 ainda mostra que todos os trechos de ruas ficaram abaixo de $50 \%$ do Índice ideal de árvores por quilômetro de calçada, sendo que a média deste índice na ZCH foi de 13,23 , representando menos de $14 \%$ do recomendado.

Rossatto, Tsuboy e Frei (2008) na cidade de Assis - SP chegaram a um valor do índice de aproximadamente 38 árvores por quilometro de calçada. Em Rio Branco - AC, Paiva et. al. (2010) encontrou o índice de 4,57 árvores por quilômetro de calçada. Já em Colorado-RS, Raber e Rebelato (2010), encontraram um número de 43 árvores por quilômetro de calçada. Logo, percebe-se que também em algumas outras cidades, este índice também não foi satisfatório. 
A zona estudada apresenta um número de árvores sete vezes menor do que o índice ideal. A tabela 1 fornece informações específicas de cada rua quanto ao IAQC sem fazer generalizações, e serve de base para intervenções nessa área, visto que a área representa um patrimônio histórico para a cidade.

Um diagnóstico preciso da arborização em uma cidade leva a um planejamento estratégico adequado para cada setor dentro do espaço, fazendo com que ações diferentes sejam propostas para locais diferentes. Ainda na tabela 1, observa-se que a Travessa Coronel Tancredo que deveria ter 90 árvores, porém não contém nenhuma!

Segundo Parry et al. (2012), a arborização de Altamira - PA não é uniforme e nos bairros centrais são encontrados a maior quantidade de árvores plantadas, em relação aos bairros periféricos. Lembrando-se que a $\mathrm{ZCH}$ localiza-se no Bairro Centro, pode-se concluir que os outros bairros da cidade de Altamira estão com o IAQC inferior ao da Zona estudada que já é um índice inadequado.

O questionário foi realizado com 43 pessoas. A maioria dos entrevistados possuía idades entre 12 e 31 anos, e a menor quantidade estava compreendida entre 72 e 91 anos (Figura 5). Esse resultado mostra que a pesquisa foi aplicada em pessoas com diferentes faixas etárias e será possível observar as percepções sobre arborização urbana nas diferentes gerações de pessoas.

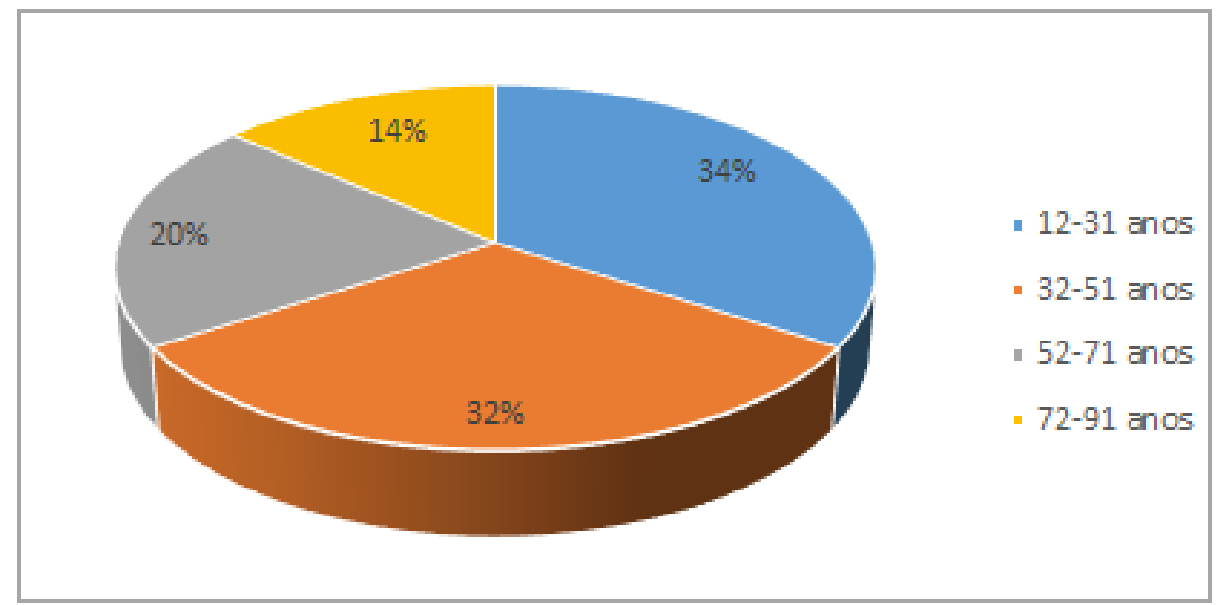

Figura 5. Quantidade de entrevistados por idade

Figure 5. Number of respondents by age

Os 15 entrevistados de idades entre 52 e 91 anos relataram a existência de uma maior quantidade de árvores com ênfase nas espécies de mangueira (Mangifera indica) há 10 anos. Isso ficou claro com as seguintes falas dos entrevistados: n5 "Era só Mangueira, só nesta rua tinha quatro, na outra tinha três", no 28 "Muita árvore, bastante mangueira", no 04 "Aqui era muito mais organizado com mangueiras, tinha mais árvores" e № 34 "Muita manga, pessoal tinha tudo". Destes 15 entrevistados, 14 eram moradores, portanto é plausível atrelar 
as similaridades nas respostas da pergunta sobre a situação da arborização há dez anos atrás e a idade deste grupo de entrevistados.

Sobre a característica de moradia dos entrevistados que se encontravam na $\mathrm{ZCH}$, o questionário foi aplicado em uma maior quantidade de moradores do bairro em relação a não moradores e comerciantes locais, como se pode visualizar na Figura 6.

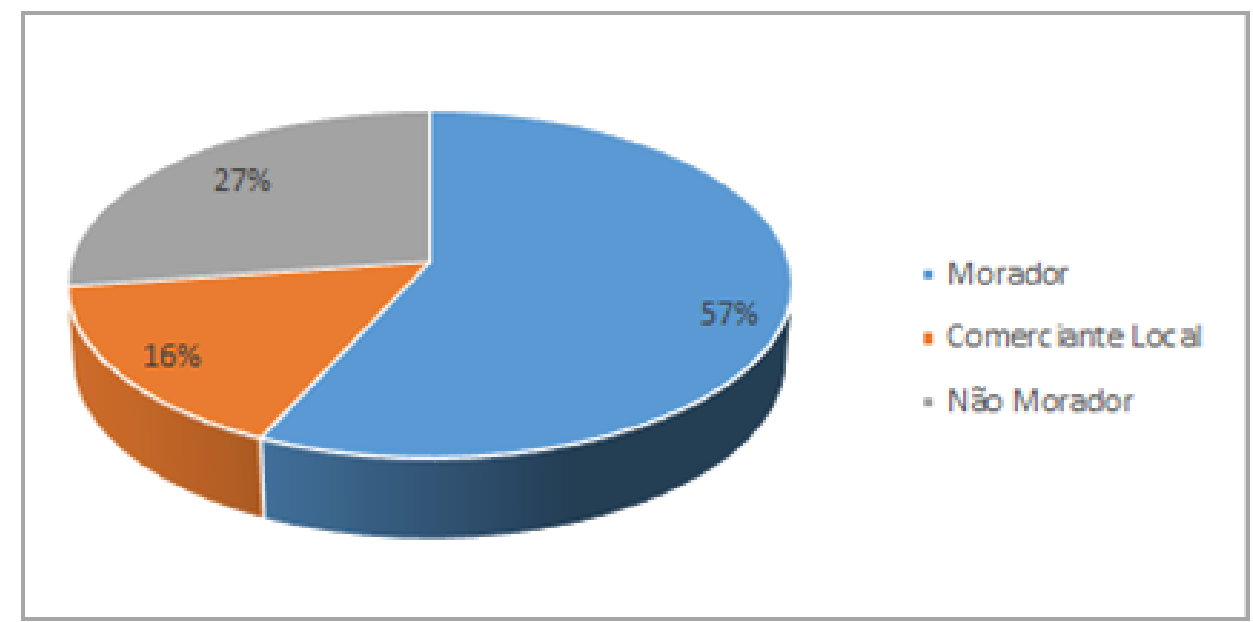

Figura 6. Quantidade de entrevistados por característica de moradia Figure 6 . Number of respondents by housing characteristics

A maioria da população entrevistada apresentou uma insatisfação sobre a quantidade de árvores existentes no bairro (Figura 7). Essa insatisfação mostra que as pessoas que moram ou que passam por esse bairro sentem a necessidade de mais árvores e essas percepções são importantes dentro de reuniões participativas para o planejamento da cidade.

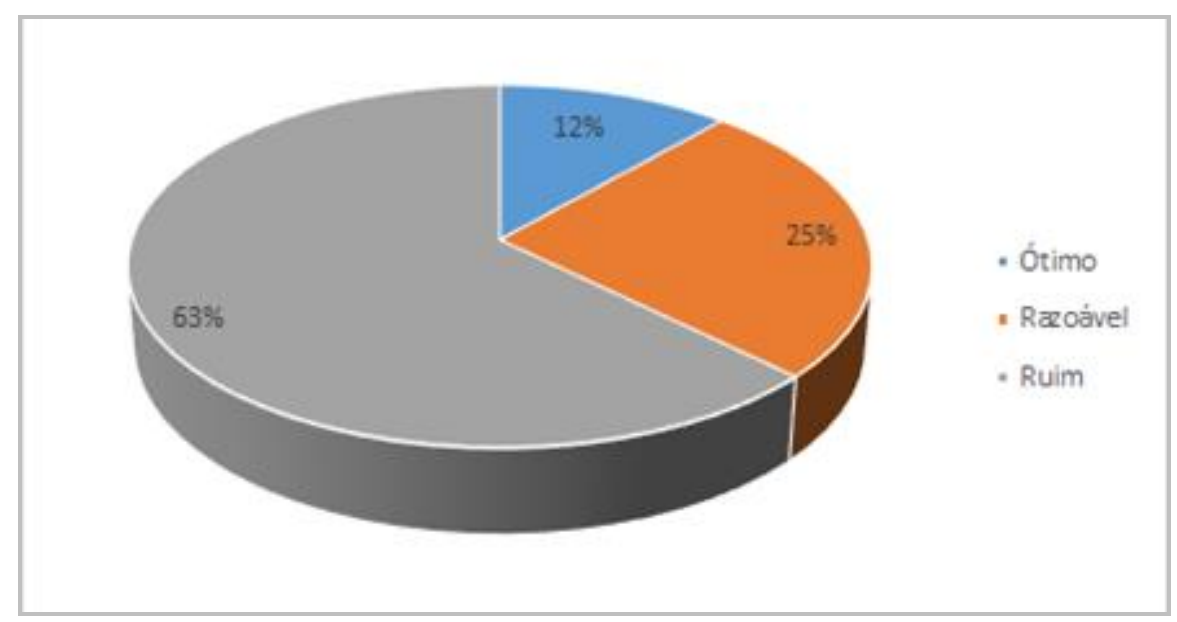

Figura 7. A percepção dos entrevistados quanto a quantidade de árvores no bairro Figure 7 . The perception of respondents as the amount of trees in the neighborhood 
Sobre as vantagens da arborização urbana, a sombra e a redução de calor são as principais vantagens citadas pelos entrevistados, correspondendo a $48 \%$ e $38 \%$, respectivamente (Figura 8 e 9). Nota-se que o fator "valorização imobiliária" não foi apontando por nenhum entrevistado como uma vantagem da arborização.

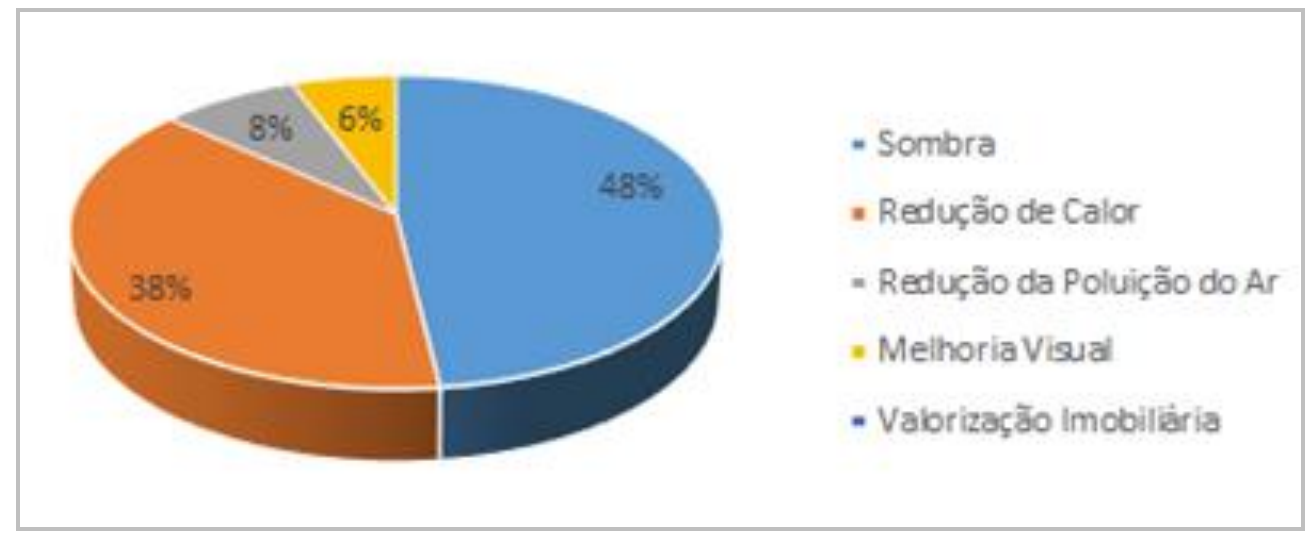

Figura 8. Percepção dos entrevistados quanto as vantagens da arborização no bairro Figure 8. Perception of respondents as the benefits of afforestation in the neighborhood

O sombreamento que a arborização proporciona foi apontado pela maioria dos entrevistados (48\%) como a principal vantagem da mesma. O sombreamento beneficia os pedestres que se deslocam com mais conforto sob a sombra das árvores e também os automóveis que estejam estacionados no acostamento dessas vias, diminuindo a temperatura interna (ALMEIDA; RONDON NETO, 2010).

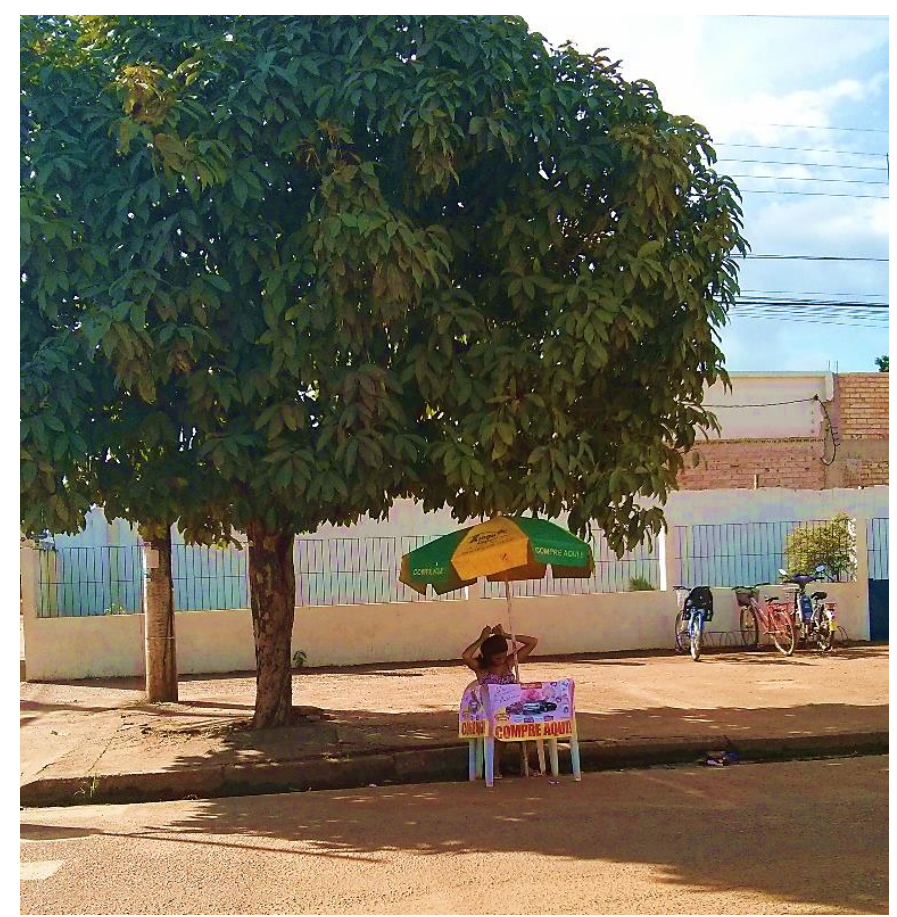

Figura 9. Árvore na rua Sete de Setembro proporcionando sombra

Figure 9. Tree on the street Sete de Setembro providing shade 
Quando questionados sobre as desvantagens, os entrevistados deram respostas como: "As árvores estão chegando a fiação de energia elétrica, e tem que pagar pra cortar". Com isso fica claro que planos de poda e manutenção das árvores não existem ou não estão sendo operados de maneira eficiente no bairro.

A ZCH possui alguns problemas relacionados a arborização, que foi realizada de forma não planejada, tais como: calçadas e muros rachados pelas grandes raízes, copa das árvores em contato com a rede elétrica, obstrução de placas de sinalização bem como a iluminação das vias públicas, indicados na Figura 10.

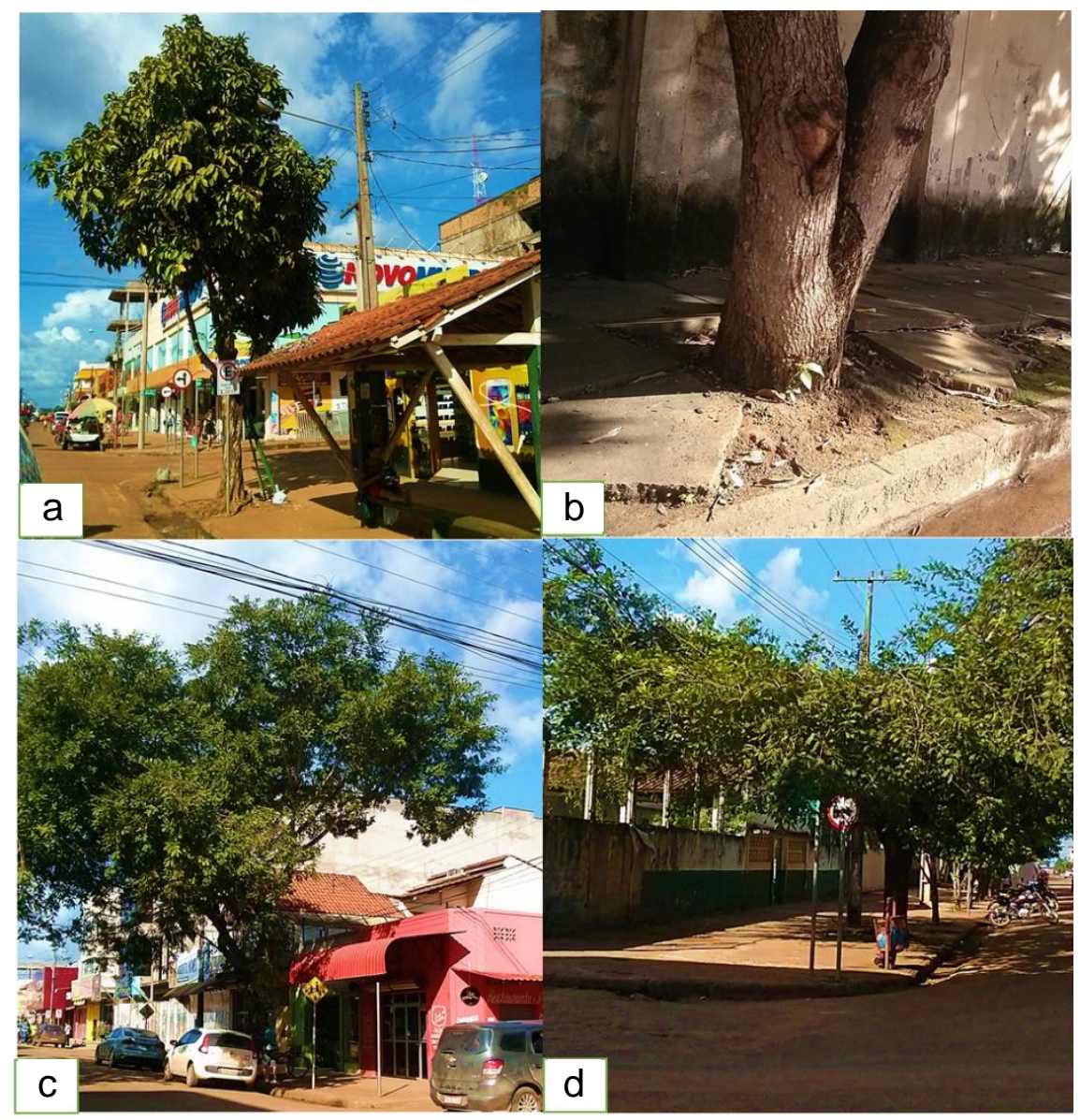

Figura 10. a) Árvore prejudicando a iluminação pública; b) Raízes da árvore quebrando a calçada; c) Árvore obstruindo a sinalização; d) Copa da árvore em contato com a rede elétrica no centro de Altamira

Figure 10. a) Tree harming public lighting; b) Tree roots breaking the pavement; c) Tree blocking the signaling; d) Treetop contact the grid in the center of Altamira

Conforme alguns entrevistados relataram, o plantio da maioria das árvores da $\mathrm{ZCH}$ foi realizado em meados da década de 1970, e muitas dessas árvores foram plantadas pelos próprios moradores. Segundo Parry et al. (2012), a falta de conhecimento das recomendações técnicas e da legislação urbana por grande parte da população leva ao plantio indiscriminado de espécies impróprias pelas características fisiológicas e inadequadas 
pelas suas características morfológicas, o que leva ao conflito dessas espécies com o a infraestrutura da cidade.

A manutenção das árvores, conforme a população fica a desejar e algumas vezes é realizada pelos próprios moradores, causando custos financeiros. Almeida e Rondon Neto (2010) afirmam que é necessária atenção na escolha das espécies a ser plantadas, pois árvores que podem atingir 10 metros necessitam de tempo e dinheiro dos órgãos competentes e dos próprios moradores para manter essas árvores.

A malha urbana do município de Altamira-PA teve uma grande expansão a partir da instalação da UHE Belo Monte no ano de 2010, devido ao incremento populacional que o empreendimento atraiu, principalmente ao cetro urbano (MIRANDA NETO, 2015). Analisando esses fatores, deveriam ser considerados aos projetos de compensação ambiental da Hidrelétrica a arborização e a manutenção da mesma, já que a obra contribuiu para a intensificação de problemas ambientais na cidade.

Segundo Lacerda et al. (2010) a arborização urbana deve fazer parte dos programas de governo das prefeituras, já que a qualidade do meio ambiente vai refletir no bem estar e na qualidade de vida dos munícipes.

O conhecimento da percepção da população do local permite que a tomada de decisões, em relação a arborização, tenha uma eficiência maior. Isso fica claro com o estudo de Costa e Colesanti (2011), o qual mostra que a percepção aplicado as áreas verdes está em conhecer o mundo de aspirações e anseios daqueles que são os principais usuários desses espaços no meio urbano, contribuindo assim, para a melhoria do ambiente e consequentemente a melhoria da qualidade de vida dos habitantes.

\section{CONCLUSÕES}

O georreferenciamento das árvores dentro da Zona Central Histórica utilizado nesse trabalho é uma ferramenta fundamental para análise espacial da distribuição das árvores. 0 Índice de Arborização por Quilômetro de Calçada na ZCH está muito abaixo do ideal, logo nas outras zonas da cidade este índice pode estar pior.

A maioria dos entrevistados está insatisfeito com a arborização da Zona, o que se deve ao fato de a quantidade de árvores plantadas ser baixa e a falta de manutenção nas mesmas, que acaba por prejudicar a infraestrutura urbana e pode colocar a população em risco.

A instalação da UHE Belo Monte acarretou numa rápida expansão urbana da cidade de Altamira-PA, nesses últimos cinco anos, e questões como a manutenção do patrimônio 
cultural, no que tange à arborização, podem não estar sendo tão consideradas nos projetos de compensação ambiental.

\section{REFERÊNCIAS}

ALMEIDA, D. N.; RONDON NETO, R. M. Análise da arborização urbana de três cidades da região norte do Estado de Mato Grosso. Revista Árvore, Viçosa-MG, v. 34, n. 5, p. 899 - 906 , 2010.

CONWAY, T. M.; BANG, E. Willing partners? Residential support for municipal urban forestry policies. Urban Forestry \& Urban Greening, Amsterdã, v. 13, n. 2, p. 234-243, 2014.

COSTA, R. G. S.; COLESANTI, M. M. A contribuição da percepção ambiental nos estudos das áreas verdes. RA'E GA, Curitiba - PR, v. 22, p. 238 - 251, 2011.

GERSTENBER, T.; HOFMANN, M. Perception and preference of trees: A psychological contribution to tree species selection in urban areas. Urban Forestry \& Urban Greening, Amsterdã, v. 15, p.103-111, 2016.

IBGE - Instituto Brasileiro de Geografia e Estatística. Censo 2010. Disponível em: <http://www.ibge.gov.br>. Acesso em: 20 de dez. de 2015.

LACERDA, N. P.; SOUTO, P. C.; DIAS, R. S.; SOUTO, L. S.; SOUTO, J. S. Percepção dos residentes sobre a arborização da cidade de São José de Piranhas - PB. Revista da Sociedade Brasileira de Arborização Urbana, Piracicaba - SP, v. 5, n. 4, p. 81-95, 2010.

LIMA NETO, E. M. de. Aplicação do sistema de informações geográficas para o inventário da arborização de ruas de Curitiba, PR. Curitiba, 2011. Dissertação (Mestre em Engenharia Florestal) - Universidade Federal do Paraná, Curitiba - PR, 2011.

MAYER, C. L. D.; FILHO, P. C. O.; BOBROWSKI, R. Análise espacial de conflitos da arborização de vias públicas: caso Irati, Paraná. Revista Floresta, Curitiba - PR, v. 45, n. 1, p. $11-20,2015$.

MIRANDA NETO, J. Q. de. UHE Belo Monte e a reestruturação da cidade de Altamira-PA: Agentes, processos e redefinições espaciais. In: ENCONTRO NACIONAL DA ASSOCIAÇÃO NACIONAL DE PÓS-GRADUAÇÃO E PESQUISA EM GEOGRAFIA, 11., 2015, Presidente Prudente - SP. Anais... ANGEPE, 2015. p. 2502 - 2513.

MOURA, A. R.; RIBEIRO, J. C. Altamira no contexto geográfico. Belém, PA: Ed. Do Autor, 2009. 119p.

OLDFIELD, E. E.; WARREN, R. J.; FELSON, A. J.; MARK A. BRADFORD. M. A. Challenges and future directions in urban afforestation. Journal of Applied Ecology, London, v. 50, p. 1169 - 1177, 2013.

PAIVA, A. V. de; LIMA, A. B. M.; CARVALHO, A.; ARNALDO M. JUNIOR, A. M.; GOMES, A.; CASSIA S. MELO, C. S.; FARIAS, C. O.; REIS, C.; CLIVIA BEZERRA, C.; JUNIOR, E. A.S.; MACEDO, E.; LIMA, E. S.; SOBRINHO, F.; SILVA, F. M.; BONFIM, J. C.; JUNIOR, L. S.; CORREA, M.; DUMONT, M. L.; JUNIOR, M. A. I.; PANTOJA, N. V.; DAVILA, R. M.; GABRIEL, 
R.; SILVA, R. A.; CUNHA, R. M.; OLIVEIRA, R. S.; DIAS, R.; NICHELI, S. P.; COSTA, S.; SOUZA, T. C.; PEREIRA, T. F.; CASTELO, Z.; FERRARI, Z. S. Inventário e diagnóstico da arborização urbana viária de Rio Branco, AC. Revista da Sociedade Brasileira de Arborização Urbana, Piracicaba - SP, v.5, n.1, p.144-159, 2010.

PARRY, M. M.; SILVA, M. M; SENA, I. S.; OLIVEIRA, F. P. M. Composição florística da arborização da cidade de Altamira, Pará. Revista da Sociedade Brasileira de Arborização Urbana, Piracicaba - SP, v.7, n.1, p. 143-158, 2012.

PIZZIOLO, B. V.; TOSTES, R.; SILVA, K.; ARRUDA, V. M. Arborização urbana: Percepção ambiental dos moradores dos bairros Bom Pastor e Centro da cidade de Ubá/MG. Revista Eletrônica em Gestão, Educação e Tecnologia Ambiental, Santa Maria, v. 18, n. 3, p.11621169, 2014.

RABER, A. P.; REBELATO, G. S. Arborização viária do município de colorado, rs - brasil: análise quali-quantitativa. Revista da Sociedade Brasileira de Arborização Urbana, Piracicaba - SP, v.5, n.1, p.183-199, 2010.

ROSSATTO, D. R.; TSUBOY, M. S. F.; FREI, F. Arborização urbana na cidade de Assis-SP: uma abordagem quantitativa. Revista da Sociedade Brasileira de Arborização Urbana, Piracicaba - SP, v.3, n.3, p.1-16, 2008.

SILVA, D. A.; BATISTA, D. B.; BATISTA, A. C. Percepção da população quanto a arborização com mangifera indica I. (mangueira) nas ruas de Belém - PA. Revista da Sociedade Brasileira de Arborização Urbana, Piracicaba - SP, v.10, n.1, p. 1-18, 2013.

SOUZA, S. M.; CARDOSO, A. L.; SILVA, A. G. Estudo da percepção da população sobre a arborização urbana, no município de Alegre-ES. Revista da Sociedade Brasileira de Arborização Urbana, Piracicaba - SP, v.8, n.2, p. 68-85, 2013.

VALENTIM, L. S. O. Sobre a produção de bens e males nas cidades: Estrutura urbana e cenário de risco à saúde em áreas contaminadas da Região Metropolitana de São Paulo. São Paulo, 2010. Dissertação (Doutorado em Arquitetura e Urbanismo) - Faculdade de Arquitetura e Urbanismo de São Paulo, São Paulo - SP, 2010. 